\title{
Patient profiles and clinical utility of mepolizumab in severe eosinophilic asthma
}

This article was published in the following Dove Press journal:

Biologics:Targets and Therapy

27 June 2017

Number of times this article has been viewed

\section{Pranabashis Haldar}

Respiratory Biomedical Research Unit, Glenfield Hospital, University of Leicester, Leicester, UK
Correspondence: Pranabashis Haldar Respiratory Biomedical Research Unit, Glenfield Hospital, Leicester LE3 9QP, UK

Tel +44 I I 6256384 I

Email ph62@le.ac.uk

\begin{abstract}
Mepolizumab (Nucala $\left.{ }^{\circledR}\right)$ is an effective and specific anti-eosinophil molecular therapy that has recently been approved as add-on therapy for the management of severe eosinophilic asthma by the US Food and Drug Administration (FDA), European Medicines Agency (EMA; European Union) and more recently National Institute for Health and Care Excellence (NICE; UK). It is one of several molecular therapies in development for this indication and is illustrative of the strategic trajectory for pharmaceutical drug development taken over the past decade in several disease areas. Molecular therapies offer the prospect of improved specificity and effectiveness of biological effect. However, this necessitates a clear understanding of the underlying mechanistic pathways underpinning pathological processes, to inform drug development that yields novel more efficacious treatment options with a better clinical profile than existing agents. For the first time, utilization of molecular therapies in clinical trials is providing a novel in vivo model to characterize the association between specific pathways and clinical disease expression. It is increasingly recognized that asthma exhibits both clinical and pathological heterogeneity. It follows that a one-size-fits-all approach will not be appropriate and cost-effectiveness may only be achieved by identifying responder subgroups. This so-called personalized approach to therapy is being supported by the parallel development of companion biomarkers for clinical application. In this review, the author summarizes the clinical studies, their interpretation and the lessons learnt with mepolizumab that have informed our understanding of the approach to personalized molecular therapy in asthma.
\end{abstract}

Keywords: IL-5, Nucala, exacerbations

\section{Introduction}

Refractory asthma, defined as a failure to achieve satisfactory asthma control despite adherence to high-dose inhaled therapies, comprises approximately $5 \%$ of the asthma population. ${ }^{1}$ Despite this, it is estimated that $60 \%$ of asthma health care costs are attributable to refractory asthma ${ }^{2}$ and more than $50 \%$ of asthma fatalities are recorded in patients with a prior history of severe disease. ${ }^{3}$ Morbidity is attributable to disabling symptoms, frequent severe exacerbations and the long-term iatrogenic sequelae of toxic immunosuppressive therapy, most notably oral corticosteroids (OCSs). The inadequacy of available therapies and the need for novel therapeutic targets are clear and have been at the forefront of asthma research over the past two decades.

The association between eosinophilic inflammation and asthma has long been recognized. Early necropsy studies ${ }^{4,5}$ in patients dying from fatal asthma reported the identification of extensive eosinophilic inflammation and eosinophil degranula- 
tion (Charcot-Leyden crystals), accompanied by mucus hypersecretion and plugging of the small airways. Later, bronchoscopic studies demonstrated the association between asthma and eosinophilic inflammation in the airway lumen and sub-epithelial compartments of patients with milder asthma. Immunohistochemical studies identified eosinophil degranulation products and an association between the expression of CD25+ cells, elevated levels of interleukin (IL)-5 mRNA expression ${ }^{6,7}$ and IL-5 protein $^{6,8}$ in biopsy material and bronchoalveolar lavage (BAL) fluid. Overall, these observations supported the view that CD4 T-cells releasing IL-5 orchestrate the eosinophilic response in asthma, with the eosinophil playing a key effector role in asthma pathogenesis. The clinical correlation between measures of asthma control and eosinophilic inflammation in blood and BAL has been reported in several studies, ${ }^{9-11}$ while treatment with glucocorticoids to ameliorate eosinophilic inflammation in blood $^{12}$ and sputum ${ }^{13}$ has been associated with concomitant improvement in symptoms and lung function.

IL-5 belongs to a family of highly conserved and phylogenetically related growth factor cytokines that also includes IL-3, IL-4 and granulocyte monocyte colony-stimulating factor (GM-CSF). Genes coding for these proteins are closely linked on chromosome $5 \mathrm{q}$ in humans. ${ }^{14}$ IL-5 is uniquely positioned as the single most important cytokine modulating eosinophil hemopoiesis, homing and tissue survival (Figure 1). This provides an attractive pharmacological target for the development of novel anti-eosinophil therapies. In this context, it should be noted that while this review focuses on asthma, the development of "anti-IL5 therapies," including mepolizumab, has a wider indication and potential role for the management of other eosinophil-driven disorders that include eosinophilic esophagitis, ${ }^{15}$ nasal polyposis, ${ }^{16}$ hypereosinophilic syndrome, ${ }^{17}$ Churg-Strauss syndrome ${ }^{18}$ and eosinophilic and atopic dermatitis. ${ }^{19}$ IL-5 is produced by CD4+ T-cells, ${ }^{20}$ group 2 innate lymphoid cells (ILC2), mast cells and eosinophils themselves. Of these cell types, ILC2 appear to have a primary role in constitutive regulation $^{21}$ while the others upregulate expression in response to an inflammatory stimulus. The IL-5R is a type 1 cytokine receptor, with a heterodimeric structure comprising separate $\alpha$ and $\beta$ subunits. The $\alpha$-subunit confers specificity, while the $\beta$-subunit is common to IL-5 and the hemopoietins, IL-3 and GM-CSF. Functional specificity of IL-5 arises from the restricted expression of its receptor (IL-5R), predominantly on eosinophils and to a lesser extent, basophils. ${ }^{22}$

Mepolizumab is a fully humanized neutralizing $\operatorname{Ig~}_{1}$ antibody to IL-5 that sequesters the cytokine and prevents it binding with the $\alpha$-subunit of the IL-5R. Preclinical studies conducted at the start of the millennium in cynomolgus monkeys ${ }^{23}$ demonstrated the impressive anti-eosinophilic properties of the molecule. Significant and profound depletion of circulating and lavage eosinophils were observed after allergen challenge, with repression of blood eosinophil counts for 74 days after two doses of mepolizumab. The bioavailability and pharmacokinetic properties of intravenous (iv) and subcutaneous (sc) administration were comparable. Interestingly, these studies identified compartmentalization of drug distribution, with a fall in measured drug concentration from plasma to the airway and lung tissue that was accompanied by a concordant reduction in the effect on eosinophil counts. A similar gradient of effect has since been reported in humans and is discussed further in the following sections.

Clinical studies of mepolizumab in asthma are summarized in Tables 1-3, and for the purpose of this review are usefully considered in three phases: 1) an early development phase (Table 1); 2) a later development phase (Table 2) and 3 ) a validation phase (Table 3). Observations made in the studies of the early phase critically informed the scientific rationale and design principles for studies in the later development phase. This second phase successfully characterized the role of mepolizumab, and more generally eosinophils, in the clinical expression of asthma and was crucial for reviving the drug development program. The validation phase has provided robust evidence in larger and more diverse study cohorts to support the outcomes observed in development and inform biomarkers that predict a clinical response to therapy.

\section{Early development phase for clinical studies of mepolizumab in asthma}

Early clinical studies of mepolizumab offered a mixed picture. On the one hand, biological efficacy of the drug as an eosinophil suppressant was clear and consistently demonstrated; however, the studies failed to identify any improvement in the clinical end points that were measured. This discordance between clinical and biological effect was unexpected and prompted debate raising doubt for a meaningful role of eosinophils in asthma pathogenesis and, as a consequence, viability of the drug development program in asthma.

The immunobiological effects of mepolizumab in asthma were largely characterized by a series of reports arising from a single randomized, double-blind placebo-controlled study of three doses administered intravenously at monthly intervals to subjects with mild corticosteroid naive asthma ${ }^{24}$ (Table 1). Treatment was associated with a $70 \%$ reduction in terminally differentiated bone marrow eosinophils ${ }^{25}$ and 


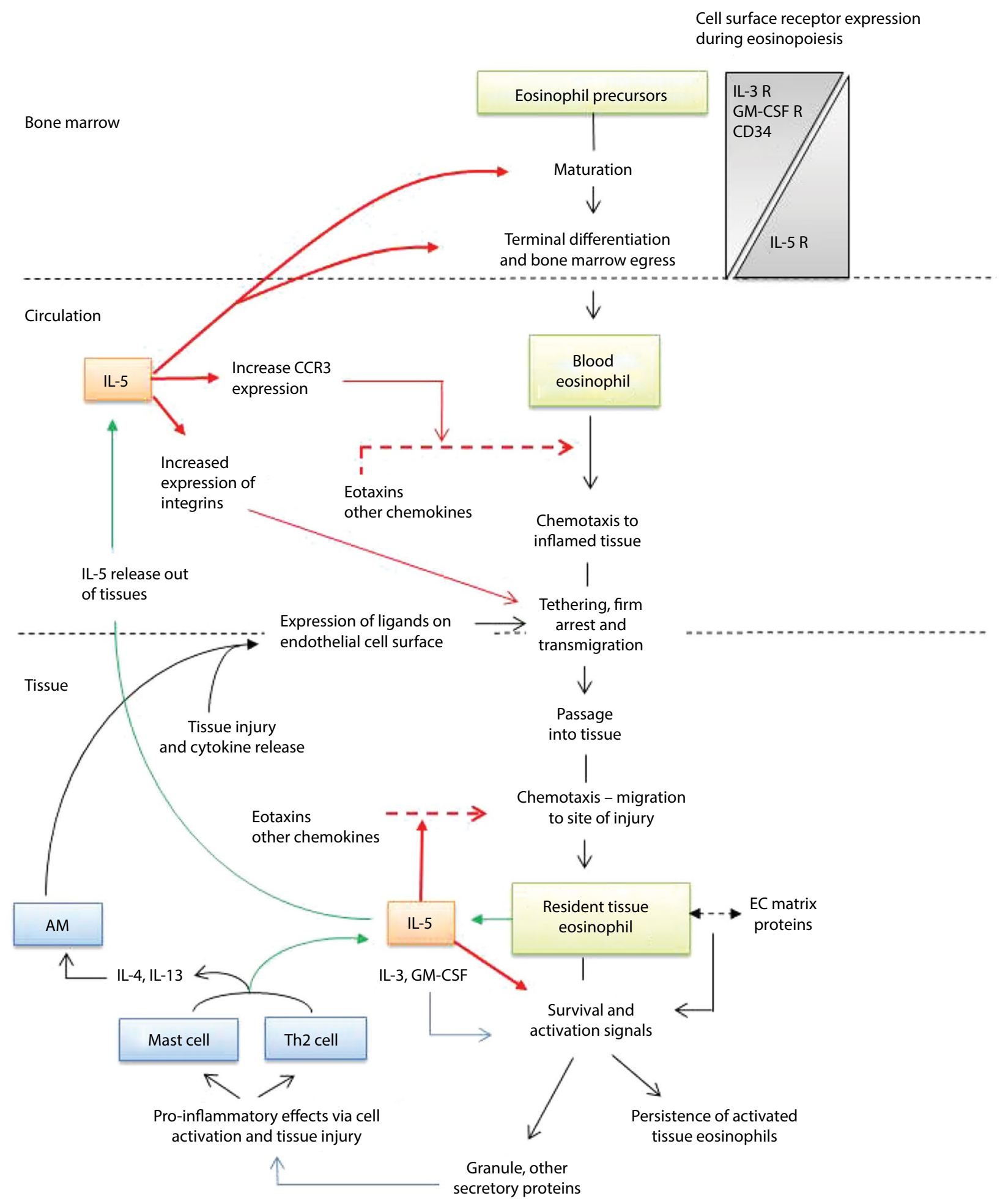

Figure I IL-5 and eosinophil biology.

Notes: Schema of factors regulating eosinophilopoiesis, homing and tissue persistence in disorders of eosinophilic inflammation. Although IL-5 is a key determinant in all three compartments of this model, other factors have an important role, particularly in eosinophil chemotaxis and tissue persistence.

Abbreviations: AM, alveolar macrophage; EC, extracellular; GM-CSF, granulocyte monocyte colony-stimulating factor; IL, interleukin.

a greater than $95 \%$ reduction in peripheral blood eosinophil counts. Consistent with the observations in cynomolgus monkeys, there was evidence for a gradient of efficacy across peripheral tissue compartments in humans, with mepolizumab achieving a reduction in eosinophil counts compared with placebo of $79 \%$ in lavage fluid and $55 \%$ in the bronchial submucosa. Despite the relative resistance of tissue eosinophils to therapy, significant effects of mepolizumab 
Table I Early Phase II clinical studies with mepolizumab

\begin{tabular}{|c|c|c|c|c|c|c|}
\hline Study & $\begin{array}{l}\text { Subject } \\
\text { characteristics }\end{array}$ & $\begin{array}{l}\text { Study } \\
\text { objective }\end{array}$ & Study design & $\begin{array}{l}\text { Primary } \\
\text { outcomes }\end{array}$ & $\begin{array}{l}\text { Secondary } \\
\text { outcomes }\end{array}$ & Comments \\
\hline \multicolumn{7}{|c|}{ Early studies (Phase II) } \\
\hline $\begin{array}{l}\text { Flood-Page } \\
\text { et al24: }(\mathrm{N}=24) \\
\text { Eosinophil's } \\
\text { role remains } \\
\text { uncertain } \\
\text { as anti-IL-5 } \\
\text { only partially } \\
\text { depletes } \\
\text { numbers in } \\
\text { asthmatic } \\
\text { airways }\end{array}$ & $\begin{array}{l}\text { Mild atopic asthma } \\
\text { managed with } \\
\text { as-required short- } \\
\text { acting beta-agonist } \\
\text { therapy alone }\end{array}$ & $\begin{array}{l}\text { To evaluate } \\
\text { the effect of } \\
\text { mepolizumab } \\
\text { on eosinophil } \\
\text { numbers in } \\
\text { blood, airways } \\
\text { (BAL), bronchial } \\
\text { mucosa and bone } \\
\text { marrow } \\
\text { To evaluate } \\
\text { the effect of } \\
\text { mepolizumab on } \\
\text { morning PEF, His } \\
\text { PC20 and FEV, }\end{array}$ & $\begin{array}{l}3 \text { doses over } \\
8 \text { weeks: } 750 \mathrm{mg} \\
\text { iv/placebo }\end{array}$ & $\begin{array}{l}\text { Change in } \\
\text { eosinophil counts } \\
\text { in different body } \\
\text { compartments: } \\
\text { - Near-complete } \\
\text { suppression } \\
\text { of blood } \\
\text { eosinophil } \\
\text { until } 9 \text { weeks } \\
\text { after final } \\
\text { mepolizumab } \\
\text { dose } \\
\text { - } \downarrow 79 \% \text { in BAL } \\
\text { - } \downarrow 55 \% \text { in } \\
\text { bronchial } \\
\text { mucosa } \\
\text { - } \downarrow 52 \% \text { in bone } \\
\text { marrow }\end{array}$ & $\begin{array}{l}\text { Change in clinical } \\
\text { parameters: } \\
\text { PEF - no change } \\
\text { FEV - no change } \\
\text { His PC20 - no } \\
\text { change }\end{array}$ & $\begin{array}{l}\text { This study elegantly } \\
\text { demonstrates the } \\
\text { differences in the } \\
\text { efficacy of mepolizumab } \\
\text { for eosinophil } \\
\text { suppression in different } \\
\text { body compartments } \\
\text { The lack of } \\
\text { clinical effect with } \\
\text { mepolizumab was } \\
\text { attributed to the } \\
\text { inability of the } \\
\text { drug to completely } \\
\text { suppress eosinophilic } \\
\text { inflammation in the } \\
\text { tissues }\end{array}$ \\
\hline 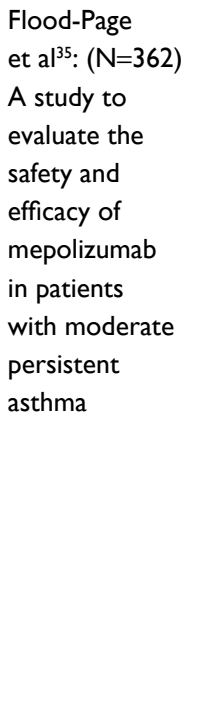 & $\begin{array}{l}\text { Moderate } \\
\text { persistent asthma: } \\
\text { - On } \leq 1000 \mu \mathrm{g} \\
\text { BDP equivalent } \\
\text { per day } \\
\text { - Persistent } \\
\text { symptoms }\end{array}$ & $\begin{array}{l}\text { To evaluate } \\
\text { the role of } \\
\text { mepolizumab } \\
\text { for symptomatic } \\
\text { asthma prior } \\
\text { to escalating } \\
\text { to high-dose } \\
\text { corticosteroid } \\
\text { therapy }\end{array}$ & $\begin{array}{l}3 \text { doses over } \\
8 \text { weeks: } \\
750 \mathrm{mg} / 250 \mathrm{mg} \\
\text { iv/placebo }\end{array}$ & $\begin{array}{l}\text { Morning PEF: } \\
\text { no significant } \\
\text { difference } \\
\text { between groups }\end{array}$ & $\begin{array}{l}\text { Change in } \mathrm{FEV}_{1} \text { : no } \\
\text { significant effect } \\
\text { Asthma symptoms: } \\
\text { no significant effect } \\
\text { Blood eosinophil } \\
\text { counts: significant } \\
\text { reduction in blood } \\
\text { eosinophils } \\
\text { Exacerbation rates, } \\
\text { categorized as mild, } \\
\text { moderate or severe: } \\
\text { no significant effect } \\
\text { overall. } \\
\text { Asthma quality of } \\
\text { life: no significant } \\
\text { effect } \\
\text { Rescue albuterol } \\
\text { use: no significant } \\
\text { effect }\end{array}$ & $\begin{array}{l}\text { Only major study } \\
\text { conducted in an } \\
\text { unselected asthma } \\
\text { population } \\
\text { Only study conducted } \\
\text { in moderate asthma } \\
\text { Only } 53 \% \text { of patients } \\
\text { who had sputum } \\
\text { induction performed } \\
\text { had eosinophilia }>3 \% \\
\text { There was a trend to } \\
\text { significant reduction in } \\
\text { severe exacerbations } \\
(p=0.06)\end{array}$ \\
\hline
\end{tabular}

Note: $\mathrm{His}$ PC20, dose of histamine required to induce a $20 \%$ reduction in $\mathrm{FEV}_{1}(\mathrm{AHR})$.

Abbreviations: AHR, airway hyperresponsiveness; BAL, bronchoalveolar lavage; BDP, beclomethasone dipropionate; FEV , forced expiratory volume in I sec; IL, interleukin; iv, intravenous; PEF, peak expiratory flow.

on airway structure were observed. Reticular basement membrane thickening, a hallmark feature of airway remodeling associated with eosinophilic airway inflammation in asthma, was significantly reduced, together with the reversal of pathological changes in the glycoprotein composition of the extracellular matrix. However, the study reported no difference of treatment compared with placebo on lung function (forced expiratory volume in $1 \mathrm{sec}\left[\mathrm{FEV}_{1}\right]$ ) and airway hyperresponsiveness (AHR; AHR refers to the demonstration of a reduction in $\mathrm{FEV}_{1}$ associated with inhalation of small doses of a bronchoconstrictor agent such as histamine. It is a hallmark of asthma. The dose of bronchoconstrictor agent required to achieve a $20 \%$ reduction in $\mathrm{FEV}_{1}$ is used to quantify the degree of AHR) to histamine challenge. ${ }^{26}$ These findings were consistent with an earlier placebo-controlled study evaluating a single dose-response of mepolizumab, administered at one of two doses $(2.5 \mathrm{mg} / \mathrm{kg}$ or $10 \mathrm{mg} / \mathrm{kg}){ }^{27}$ This study reported no effect of therapy on $\mathrm{FEV}_{1}, \mathrm{AHR}$ and the late response to allergen challenge despite a significant reduction in blood and lavage eosinophil counts. Another study using an alternative anti-IL5 agent (SCH55700) in subjects with more severe, persistent asthma with impaired lung function also failed to show an improvement in $\mathrm{FEV}_{1}$ with treatment. ${ }^{28}$ 
Table 2 Later Phase Ila clinical studies with mepolizumab

\begin{tabular}{|c|c|c|c|c|c|c|}
\hline Study & $\begin{array}{l}\text { Subject } \\
\text { characteristics }\end{array}$ & Study objective & Study design & Primary outcomes & $\begin{array}{l}\text { Secondary } \\
\text { outcomes }\end{array}$ & Comments \\
\hline \multicolumn{7}{|c|}{ Late studies (Phase Ila) } \\
\hline $\begin{array}{l}\text { Haldar et } \mathrm{al}^{44} \text { : } \\
(\mathrm{N}=6 \mathrm{I}) \\
\text { Mepolizumab } \\
\text { and severe } \\
\text { exacerbation } \\
\text { frequency in } \\
\text { refractory } \\
\text { eosinophilic } \\
\text { asthma }\end{array}$ & $\begin{array}{l}\text { Refractory asthma } \\
\text { Sputum } \\
\text { eosinophils } \\
>3 \% \text { in previous } \\
12 \text { months } \\
\geq 2 \text { exacerbations } \\
\text { in previous } \\
12 \text { months }\end{array}$ & $\begin{array}{l}\text { First phenotype- } \\
\text { specific study } \\
\text { evaluating severe } \\
\text { exacerbations as the } \\
\text { primary end point }\end{array}$ & $\begin{array}{l}\text { I } 2 \text { doses over } \\
44 \text { weeks: } \\
750 \mathrm{mg} \text { iv/ } \\
\text { placebo }\end{array}$ & $\begin{array}{l}\text { Annualized severe } \\
\text { exacerbation } \\
\text { frequency: } \downarrow 43 \%\end{array}$ & $\begin{array}{l}\text { Change in blood } \\
\text { eosinophil count: } \\
\downarrow 83 \% \\
\text { Change in sputum } \\
\text { eosinophil count: } \\
\downarrow 72 \% \\
\text { Change in ACQ-5: no } \\
\text { significant effect } \\
\text { Change in AQLQ: } \\
\uparrow 0.55 \\
\text { PC20 Mch: no } \\
\text { significant effect } \\
\text { Change in FEV }: \text { no } \\
\text { significant effect }\end{array}$ & $\begin{array}{l}\text { Only study to } \\
\text { perform serial } \\
\text { sputum eosinophil } \\
\text { counts } \\
\text { Only study to } \\
\text { characterize airway } \\
\text { inflammation at the } \\
\text { time of exacerbation: } \\
36 \% \text { of mepolizumab- } \\
\text { treated subjects had } \\
\text { a sputum eosinophilia } \\
>3 \% \text { at exacerbation } \\
\text { compared with 59\% } \\
\text { in the placebo group }\end{array}$ \\
\hline $\begin{array}{l}\text { Nair et } \mathrm{al}^{45} \text { : } \\
(\mathrm{N}=20) \\
\text { Mepolizumab } \\
\text { for prednisone- } \\
\text { dependent } \\
\text { asthma with } \\
\text { sputum } \\
\text { eosinophilia }\end{array}$ & $\begin{array}{l}\text { Refractory asthma } \\
\text { Sputum } \\
\text { eosinophils }>3 \% \\
\text { On maintenance } \\
\text { OCS for } \geq 4 \text { weeks } \\
\text { at a dose of } \\
5-25 \mathrm{mg}\end{array}$ & $\begin{array}{l}\text { To evaluate whether } \\
\text { mepolizumab could } \\
\text { be used as oral } \\
\text { steroid-sparing agent }\end{array}$ & $\begin{array}{l}5 \text { doses over } \\
16 \text { weeks: } \\
750 \text { mg iv/ } \\
\text { placebo } \\
\text { (5 doses over } \\
16 \text { weeks) }\end{array}$ & $\begin{array}{l}\text { Proportion of patients } \\
\text { having a severe } \\
\text { exacerbation with OCS } \\
\text { withdrawal: I out of } 9 \\
\text { patients (mepolizumab } \\
\text { treated) vs I0 out of } \\
\text { I I patients (placebo } \\
\text { treated) } \\
\text { OCS dose reduction } \\
\text { achieved, expressed } \\
\text { as a percentage of } \\
\text { maximum possible } \\
\text { dose reduction } \\
\text { (protocol defined): } 84 \% \\
\text { of maximal reduction } \\
\text { (mepolizumab) vs } 48 \% \\
\text { (placebo) }\end{array}$ & & $\begin{array}{l}\text { The greater } \\
\text { reductions in steroid } \\
\text { achieved compared } \\
\text { with SIRIUS (see } \\
\text { Table 3) may } \\
\text { reflect the protocol } \\
\text { which allowed } \\
\text { steroid withdrawal } \\
\text { to continue if an } \\
\text { exacerbation was } \\
\text { neutrophilic }\end{array}$ \\
\hline
\end{tabular}

Note: PC20 Mch, dose of methacholine to induce a $20 \%$ reduction in $\mathrm{FEV}$.

Abbreviations: ACQ-5, Asthma Control Questionnaire (5-point score); AQLQ, Asthma Quality of Life Questionnaire; FEV , forced expiratory volume in I sec; iv, intravenous; OCS, oral corticosteroid; SIRIUS, Steroid Reduction with Mepolizumab Study.

A mechanistic explanation for clinical inefficacy was uncertain. It was argued that three doses of mepolizumab may be insufficient, and the time period too short, to observe changes in lung physiology. ${ }^{24}$ On the other hand, the reduction in tissue eosinophils achieved with mepolizumab was comparable with the reported effect of high-dose OCS therapy, ${ }^{29}$ which does significantly improve AHR and FEV in asthma subjects with eosinophilic inflammation. In this context, two points are noteworthy: first, corticosteroids have a much broader spectrum of anti-Th2 activity that includes, but is not confined to, inhibition of eosinophilic inflammation $^{30,31}$ and second, anti-IL5 therapies promote uncoupling of eosinophilic inflammation from other Th2 processes (Figure 2). This idea is supported by the observations of a study by Büttner et $\mathrm{a}^{32}$ administering three doses of mepolizumab at monthly intervals to patients with moderate persistent asthma. Treatment was not associated with any effect on non-eosinophil leukocyte numbers, markers of T-cell activation, intracellular cytokine expression or cytokine receptor expression. It therefore follows that anti-IL5 therapies enable empirical classification of clinical variables as either being eosinophil driven and mediated (the eosinophil is an effector cell) or Th2 driven but not eosinophil mediated (the eosinophil is a biomarker). This represented a paradigm shift away from historical dogma that implicated the eosinophil as the primary effector cell in Th2-driven asthma pathogenesis and was supported by emerging evidence from other studies reporting dissociation between eosinophilic airway inflammation and AHR. 33,34

In 2007, Flood-Page et $a l^{35}$ reported on the first large-scale multicenter double-blind placebo-controlled clinical trial of mepolizumab in moderate persistent asthma (Table 1). The study enrolled 362 subjects with persistent symptoms despite treatment with inhaled corticosteroids $(\leq 1000 \mu \mathrm{g}$ 


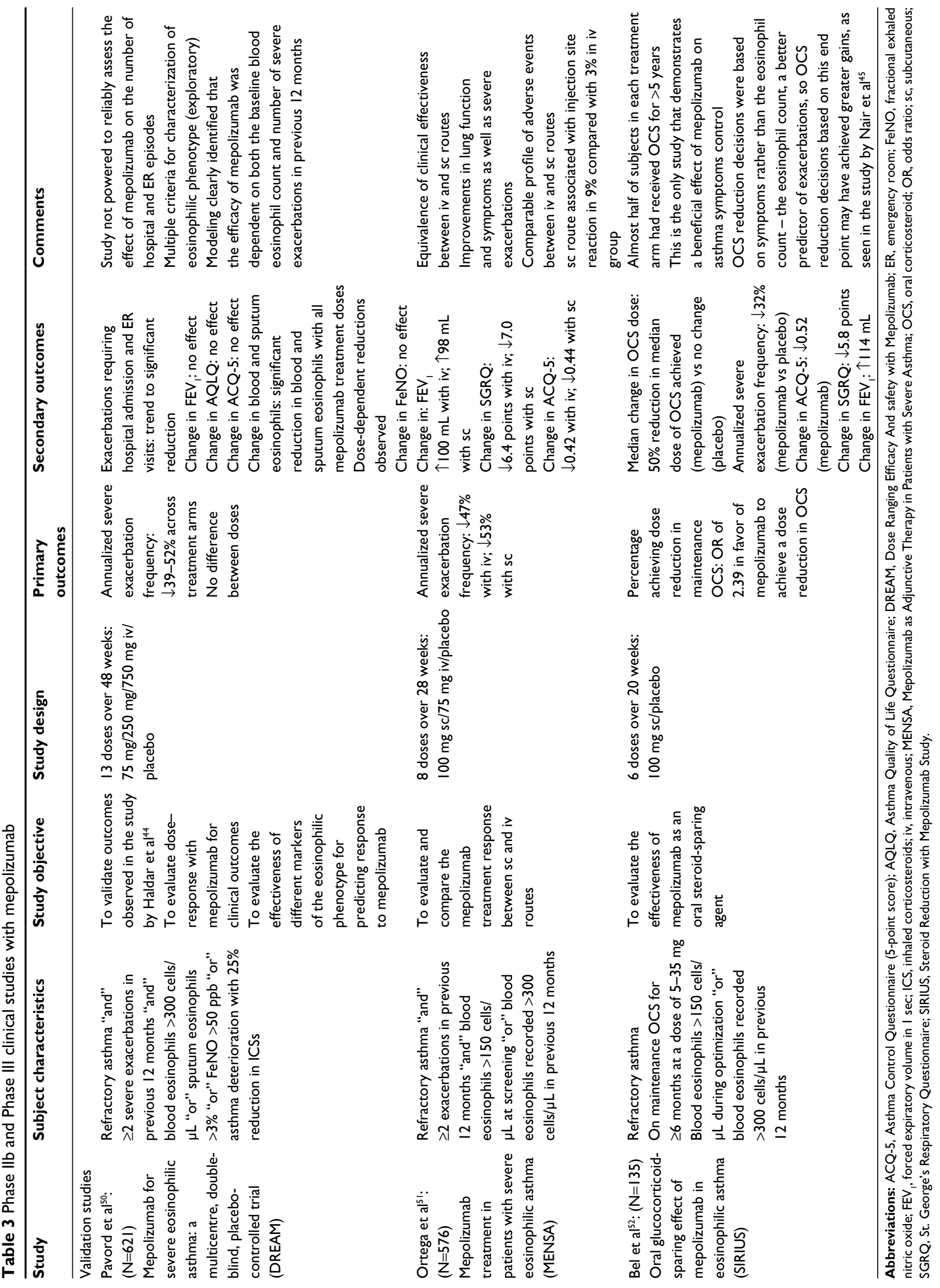




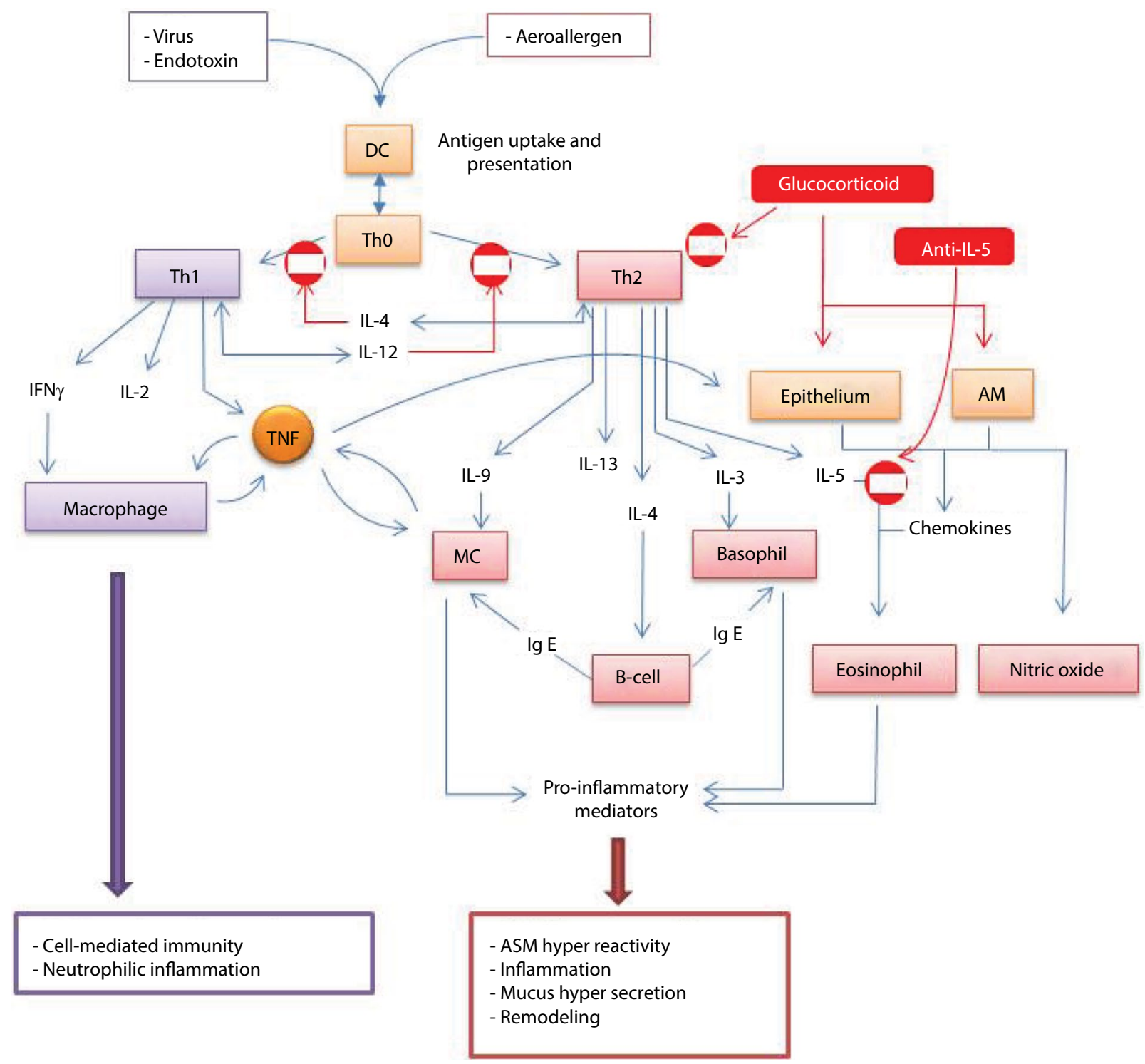

Figure 2 Adaptive immunity in asthma.

Notes: Both Th2 and ThI pathways are believed to play a role in asthma-associated chronic airway inflammation. It is increasingly recognized that while either ThI or Th2 processes may predominate, they are not exclusive. Key pro-inflammatory mediators such as TNF $\alpha$ have an important role in both pathways, enabling coexistence of inflammatory components from both pathways. Glucocorticoids have potent and broad-spectrum anti-Th2 activity. The effects of anti-IL-5 are more restricted. A comparison of clinical outcome between the two treatments offers the prospect of isolating the role of eosinophils from other Th2 factors.

Abbreviations: AM, alveolar macrophage; ASM, airway smooth muscle; DC, dendritic cell; IL, interleukin; MC, mast cell; TNF $\alpha$, tumour necrosis factor - alpha.

beclomethasone dipropionate [BDP] equivalent per day) and randomized them to 3 months of iv treatment with either one of two doses of mepolizumab (250 mg or $750 \mathrm{mg}$ ) or placebo. Subjects were followed up and data collected for 8 weeks after the final dose. Of note, a subset of 32 subjects had sputum induction performed and $17(53 \%)$ had evidence of eosinophilic inflammation. Although the study failed to show improvement in any clinical outcome measure despite significant reductions in the blood eosinophil count at both doses of active drug, a 50\% reduction in severe exacerbations was observed during the follow-up period that failed to reach statistical significance ( $p=0.06$ ) as the study was not powered for this outcome.

This review strengthened the view that traditional asthma outcome measures, notably morning peak flow, AHR and $\mathrm{FEV}_{1}$ were unlikely to be eosinophil mediated. Furthermore, there was a growing body of literature describing non-eosinophilic asthma, a condition characterized by the absence of eosinophilic airway inflammation but with clinical and physiological features that are indistinguishable from eosinophilic asthma. ${ }^{36}$ Observational studies suggested that approximately half of poorly controlled patients have a non-eosinophilic 
phenotype. ${ }^{37,38}$ Typically, these patients have a poor response to corticosteroid therapy, ${ }^{39}$ and no biological rationale for an anti-IL-5 therapy strategy. In keeping with this, $47 \%$ of participants that underwent sputum induction had an eosinophil count of $<3 \%$, suggesting a non-eosinophilic phenotype for a significant proportion of the cohort. The study was important for illustrating the perils of an unselected approach to subject enrollment, recruiting a significant non-responder group that would mask any beneficial effects of therapy. Despite this, it is notable that the study reported a trend toward reduction in severe exacerbation frequency that approached significance $(p=0.06)$, supporting an effect of treatment on this clinical outcome for the subgroup of subjects that were likely responders. This was in keeping with a growing body of evidence from other sources implicating eosinophilic airway inflammation in the pathogenesis of severe exacerbations, including the previously described necropsy studies of fatal asthma; ${ }^{4,5}$ studies reporting a rising sputum eosinophil count prior to and during exacerbations; ${ }^{40}$ and studies demonstrating a significant reduction in exacerbation frequency achieved with a management approach titrating corticosteroid therapy to regular sputum eosinophil counts, independent of other measures of asthma control. ${ }^{41-43}$

While the early clinical experience with mepolizumab was disappointing, significant gains were made in three key areas: first, the studies were reassuring for demonstrating biological efficacy; second, mepolizumab enabled a step change in our understanding of the relationship between eosinophilic inflammation and asthma pathogenesis and third, it became clear that translational studies of specific molecular therapies when applied to disorders such as asthma that express considerable pathological and clinical heterogeneity would need to be designed to be "phenotype specific" (directed to the subgroup of patients who are likely responders) and "outcome specific" (directed to end points that are likely to be associated with the biological effect of the therapy). These lessons critically informed subsequent studies and have almost certainly influenced the drug development program of other molecular therapies for asthma.

\section{Late development phase for clinical studies of mepolizumab in asthma}

In 2009, two independent small-scale single-center Phase II proof-of-concept studies were published that were the first to evaluate mepolizumab in asthma using a phenotype and outcome-specific approach (Table 2). The studies were complementary in their design and outcome and informed the design of subsequent larger phase IIb and Phase III studies.
Haldar et $\mathrm{al}^{44}$ investigated the effect of 12 doses of mepolizumab (750 mg iv given at four weekly intervals) on severe exacerbation frequency in 61 subjects with well-characterized refractory eosinophilic asthma and a history of recurrent severe exacerbations. In the study by Nair et al, ${ }^{45} 20$ subjects with refractory eosinophilic asthma requiring maintenance prednisolone therapy for control were randomized to evaluate the effect of five doses of mepolizumab (750 $\mathrm{mg}$ iv given at four weekly intervals) on the dose reduction in prednisolone achieved, titrated to the occurrence of severe eosinophilic exacerbations. There is a strong mechanistic rationale ${ }^{46}$ for complementary effects of treatment with mepolizumab and OCSs in patients with severe eosinophilic asthma. In particular, blockade of IL-5 with mepolizumab lowers the number of circulating eosinophils and this synergises with the inhibitory effects of corticosteroids on eosinophil chemotaxis (suppression of eotaxins) ${ }^{47}$ and eosinophil effector function (suppression of eosinophil cationic protein - a dominant eosinophil granule protein responsible for tissue damage). ${ }^{48}$ Mepolizumab can therefore support successful corticosteroid dose reduction by contributing effectively to lowering levels of tissue eosinophilia.

Both studies used a targeted approach to recruitment, focusing on subjects with an eosinophilic phenotype of refractory asthma. Both studies also included severe exacerbations as the primary evaluation end point. The eosinophilic phenotype was defined in both studies by evidence of a sputum eosinophil count of greater than $3 \%$ on serial longitudinal measurement. In the study by Haldar et $\mathrm{al},{ }^{49}$ the inclusion of a requirement for subjects to have had a history of recurrent severe exacerbations (two or more per year) is notable, following the group's previously reported observation that the eosinophilic phenotype of asthma itself is heterogeneous, with a proportion of such patients having persistent eosinophilia but infrequent exacerbations. Thus, persistent eosinophilic inflammation confers a risk of severe exacerbations but does not predict that exacerbations will occur. It follows that the identification of recurrent exacerbations in the presence of eosinophilic inflammation would identify the subgroup of eosinophilic patients in whom the relationship between eosinophilic inflammation and exacerbation events is strongest, such that an anti-eosinophil strategy would have greatest impact on exacerbation prevention. In the study by Nair et al, ${ }^{45}$ this subgroup was self-selected as all patients were prednisolone dependent on a clinical background of eosinophilic inflammation associated with poor control and recurrent exacerbations.

In contrast with the early clinical studies, mepolizumab demonstrated significant clinical efficacy for the primary 
end point of both of these trials (Table 1). In the study by Haldar et $a 1,{ }^{44}$ mepolizumab was associated with a $43 \%$ reduction in severe exacerbations, compared with placebo, over 48 weeks. Consistent with earlier studies, the drug had no significant effect on symptom scores (Asthma Control Questionnaire [ACQ]), lung function (post-bronchodilator $\mathrm{FEV}_{1}$ ) or AHR (methacholine PC20). Asthma Quality of Life Questionnaire (AQLQ) did improve and this was attributed to better exacerbation control. Biological efficacy was consistent with previous studies, with mepolizumab achieving an $83 \%$ greater reduction in blood eosinophil count compared with placebo over 48 weeks. The Haldar et al's study remains the only study to have performed systematic serial sputum eosinophil count monitoring and reported a $72 \%$ reduction in sputum eosinophils compared with placebo over 48 weeks. In contrast with the relatively homogeneous blood eosinophil response to treatment, the suppression of sputum eosinophils with mepolizumab treatment was more heterogeneous. A significant correlation between the number of exacerbations and area under the curve sputum eosinophil count over 48 weeks was observed, implicating a causal role for airway eosinophils in the pathogenesis of exacerbations. In the study by Nair et al, ${ }^{45}$ mepolizumab therapy was associated with a significantly greater reduction in prednisolone dose, expressed as a percentage of the maximum achievable per protocol reduction ( $84 \%$ vs $48 \%$, Table 2). Ten of 11 subjects in the placebo arm experienced exacerbations with prednisolone withdrawal and nine of 12 exacerbations in this group were eosinophilic. In contrast, only one subject receiving mepolizumab had an exacerbation with steroid withdrawal and this was of a non-eosinophilic phenotype.

Overall, the observations of the studies by Haldar et al and Nair et al strengthen the view that mepolizumab, and probably specific anti-eosinophil treatment strategies more generally, are best suited to the management of eosinophilic patients with frequent severe exacerbations. For this phenotype, eosinophilic airway inflammation is a primary driver of exacerbation risk, such that effective suppression of this inflammation with treatment is associated with a corresponding reduction in severe exacerbations.

\section{Validation phase for clinical studies of mepolizumab in asthma}

The positive outcomes presented in the studies by Haldar et $\mathrm{al}^{44}$ and Nair et $\mathrm{al}^{45}$ provided sufficient evidence for investment into three larger Phase IIb and Phase III validation studies with the following objectives (Table 3 ):
1. Clinical: To validate that treatment with mepolizumab is associated with the clinical outcomes of a significant reduction in severe exacerbations and/or maintenance OCS dose in cohorts with an eosinophilic phenotype of asthma.

2. Pharmacological: To determine the dose, schedule and route of administration of mepolizumab achieving clinical effectiveness.

3. Phenotypic: To characterize biomarkers and patient characteristics that define the responder population for mepolizumab treatment.

These objectives have been supported by additional post hoc analyses of pooled study data. All three primary studies were conducted as multicenter, multinational, placebo-controlled double-blind parallel group clinical trials.

\section{Objective Ia: validating the effectiveness of mepolizumab for lowering severe exacerbation frequency}

Two of the validation studies - the Dose Ranging Efficacy And safety with Mepolizumab (DREAM) study ${ }^{50}$ and Mepolizumab as Adjunctive Therapy in Patients with Severe Asthma (MENSA) $)^{51}$ - used severe exacerbation frequency as their primary clinical end point. Both studies selectively recruited patients with a likely eosinophilic phenotype and history of frequent severe exacerbations ( $\geq 2$ per year). Treatment duration in DREAM was longer with subjects receiving 13 doses of treatment at four weekly intervals, compared with eight doses for MENSA.

The key difference between these studies helped to inform objective 2: DREAM was a Phase IIb study designed to compare the effectiveness of differing doses of iv therapy, while MENSA was designed to compare the effectiveness of mepolizumab administered at biologically equivalent doses administered by either the iv or sc route. In addition, the DREAM study helped to inform objective 3 by incorporating a breadth of criteria to identify the eosinophilic phenotype. These included either direct demonstration of eosinophilic inflammation (elevated blood or sputum eosinophil counts) or factors recognized to have an association with a Th2 high state (elevated fractional exhaled nitric oxide [FeNO] and symptom deterioration with lowering of inhaled corticosteroid dose).

Both DREAM and MENSA reported an approximate halving of annualized severe exacerbation frequency (39-52\% rate reduction across different treatment subgroups) for mepolizumab compared with placebo that was entirely 
consistent with the reported effect in the study by Haldar et al. ${ }^{44}$ Furthermore, DREAM identified no significant effect of mepolizumab on lung function $\left(\mathrm{FEV}_{1}\right)$, symptom scores (modified ACQ-5) or AQLQ. This was largely in keeping with Haldar et al, although Haldar et $\mathrm{al}^{44}$ had reported an improvement in asthma quality of life that was attributed to the benefit of a lowering in exacerbation-related morbidity. In contrast, MENSA reported significant improvements in all three secondary outcome measures. Reasons for these differences are unclear; however, it is possible that any positive effect of mepolizumab on these outcome measures could be masked by improvements in these measures achieved by more frequent use of short-course corticosteroids to treat exacerbations in the placebo group. In this context, it is notable that the exacerbation frequency in the placebo arm of MENSA was lower (1.74 per year) than both Haldar et al (3.4 per year) and DREAM (2.4 per year).

\section{Objective Ib: validating the effectiveness of mepolizumab for enabling dose reductions in maintenance OCS therapy}

The Steroid Reduction with Mepolizumab Study (SIRIUS) ${ }^{52}$ was a Phase III study designed to validate the findings of Nair et $\mathrm{a}^{45}$ for effectiveness of mepolizumab to achieve successful dose reductions in maintenance OCSs for patients with severe refractory eosinophilic asthma and oral steroid dependence. The study was of shorter duration than the other two Phase III studies and comprised treatment with six doses of either mepolizumab (100 mg sc) or placebo at four weekly intervals. Recruitment criteria included evidence of an eosinophilic phenotype and oral steroid dependence for a period of $\geq 6$ months at a dose of between $5 \mathrm{mg}$ and $35 \mathrm{mg}$. It is well recognized that OCS therapy is a powerful suppressant of the blood eosinophil count, yet the study investigators elected to identify the eosinophilic phenotype on the basis of a blood eosinophil count of either $>300$ cells $/ \mu \mathrm{L}$ at any time in the preceding 12 months or $>150$ cells $/ \mu \mathrm{L}$ during the study optimization phase - a period prior to randomization when subjects had their regular dose of OCSs systematically reduced at weekly intervals until they either had an exacerbation or their symptom scores increased by 0.5 points on the ACQ-5. The latter criterion would identify subjects in whom unmasking of underlying eosinophilic inflammation occurred with steroid withdrawal. Selection criteria to the study therefore favored recruitment of subjects with evidence of either relative steroid resistance or a potent eosinophilic drive. The inclusion of an optimization phase ensured that subjects had borderline asthma control at treatment baseline, enabling the "added value" of mepolizumab to be examined. There were some important differences between SIRIUS and the other mepolizumab studies that have been described. A prior history of frequent severe exacerbations, was not an inclusion criterion and in contrast with the study by Nair et $\mathrm{al},{ }^{45}$ the protocol for steroid withdrawal during the treatment phase was based on clinical control alone and did not take into account eosinophilic inflammation. While practical, an implication of this approach was that the effectiveness of mepolizumab as a steroid-sparing agent relied on eosinophilic inflammation being closely associated with symptom control. This is contrary to the previously described observations of a dissociation between symptoms and eosinophilic inflammation. Indeed, in the study by Nair et al, it is this dissociation that provided the scientific rationale to continue steroid withdrawal (successfully) following an exacerbation when sputum induction identified an absence of eosinophilic airway inflammation. Despite this, SIRIUS reported an odds ratio of 2.4 in favor of mepolizumab for achieving a dose reduction in oral steroids and a $50 \%$ overall reduction in the median dose of OCSs, compared with placebo. Furthermore, the study reported significant improvements with mepolizumab in asthma symptoms, lung function and quality of life that were comparable with the observations in MENSA and consistent with the idea that these "softer" effects of mepolizumab are masked in an exacerbation directed study design that permits asthma control to be achieved in placebo subjects through the use of recurrent short courses of OCSs when presenting with poor clinical control. If this is accurate, then it suggests that eosinophilic inflammation contributes to asthma symptoms, though in contrast with severe exacerbations, is not the dominant factor.

\section{Objective 2: determining the optimum dose and route of administration of mepolizumab for clinical application}

As described earlier, both DREAM ${ }^{50}$ and MENSA $^{51}$ were designed to study this objective. Outcomes from DREAM demonstrated evidence of a dose-response effect on blood and sputum eosinophil counts, with increasing doses of mepolizumab leading to greater suppression of eosinophilic inflammation; however, this was not associated with a difference in any clinical outcome measures, compared with placebo. These observations suggest a non-linear relationship between clinical outcomes and eosinophilic inflammation, with the lowest dose of mepolizumab achieving the threshold of amelioration required for clinical control. In MENSA, there was no difference in clinical or biological 
effect, compared with placebo, between iv and sc mepolizumab given at doses of $75 \mathrm{mg}$ and $100 \mathrm{mg}$, respectively. The biological efficacy of the sc route at a dose of $100 \mathrm{mg}$ has been validated in a separate dose-response study that reported $74 \%$ bioavailability of mepolizumab via the sc route and $90 \%$ suppression of the blood eosinophil count at a dose of $99 \mathrm{mg} .{ }^{53}$ Importantly, MENSA reported no excess of adverse effects with $\mathrm{sc}$ administration. As the favored route for administration in a clinical setting, the data support the use of mepolizumab $100 \mathrm{mg}$ sc for clinical practice.

\section{Objective 3: identifying biomarkers and patient characteristics that define the mepolizumab responder population}

Characterization of the so-called responder phenotype requires an understanding of the biological mechanism underpinning clinical disease expression. For mepolizumab, it is clear that responders will be patients with eosinophilic asthma and a profile of clinical disease expression for which eosinophilic inflammation has a significant role. In this context, there is consistent evidence that the risk of severe asthma exacerbations in eosinophilic patients is closely associated with their level of underlying eosinophilic inflammation. A simple bivariate model for characterizing responders may therefore include a biomarker of eosinophilic inflammation, together with a clinical history of frequent exacerbations. While the latter is easily elicited from the patient's history, there are a number of possible markers to measure eosinophilic inflammation.

\section{Biomarkers of eosinophilic inflammation}

The studies by Haldar et al and Nair et al utilized sputum eosinophilia as the marker of eosinophilic inflammation. As a disease of the airways, the sputum eosinophil count provides the most direct measure of eosinophilic inflammation that is anatomically pertinent and is generally considered to be the gold standard. However, sputum induction and processing requires expertise that precludes universal implementation.

The blood eosinophil count represents a steady state between the release of eosinophils from the bone marrow, an IL-5-driven process, and sequestration of cells in the tissues. There is evidence to support the view that asthma is associated with an increased sequestration of eosinophils in the lung parenchyma. ${ }^{54} \mathrm{~A}$ peripheral blood eosinophilia in asthma is therefore a reliable measure of IL-5 upregulation and indicates a propensity for accelerated accumulation of eosinophils within lung tissue that may be reversed with mepolizumab therapy. Other biomarkers of the Th2 pathway (Figure 2) include $\mathrm{FeNO}^{55}$ and serum periostin ${ }^{56}$ and provide a surrogate measure of likely underlying eosinophilic inflammation as a correlate of Th2 activity.

\section{The blood eosinophil count as a biomarker of mepolizumab response}

As previously described, the DREAM ${ }^{50}$ study included four different biomarkers to identify the eosinophilic responder phenotype. Of these, the baseline blood eosinophil count combined with the frequency of prior severe exacerbations was predictive in a modeling study of treatment response to mepolizumab, measured as the magnitude of relative reduction in exacerbations compared with placebo. It should be noted that sputum eosinophil counts were only available in a small subgroup of 94 participants (15\% of the study cohort) and could not be included in the model. In a post hoc analysis of the DREAM and MENSA studies, ${ }^{57}$ a positive correlation between the baseline blood eosinophil count and magnitude of treatment response with mepolizumab was identified, with a threshold baseline blood eosinophil count of 150 cells $/ \mu \mathrm{L}$ predictive of significant treatment response. However, there is a caveat that this lower threshold was demonstrated for a carefully characterized eosinophilic population. As a blood eosinophil count to identify the responder subgroup within a heterogeneous asthma population, it lacks discriminatory power, falling well within the accepted normal range for blood eosinophils in the general population. In this context, it may be useful to consider two thresholds: 1) a higher blood eosinophil count ( $>300$ cells $/ \mu \mathrm{L}$ ) to both reliably distinguish the responder population in an unselected cohort and inform mepolizumab treatment response; and 2) a lower threshold ( $>150$ cells $/ \mu \mathrm{L}$ ) for considering mepolizumab therapy in cohorts with previously well-characterized eosinophilic asthma or, as in SIRIUS, ${ }^{52}$ for patients treated with regular OCSs, in whom suppression of the blood eosinophil count is expected.

\section{Multidimensional phenotyping to characterize patient phenotypes of response}

Multidimensional phenotyping using techniques such as cluster analysis provides a holistic and objective approach to identifying subgroups with shared characteristics within a heterogeneous population ${ }^{58}$ and has been used extensively in characterizing asthma phenotypes. ${ }^{49,59}$ In a post-hoc analysis of the DREAM study, cluster analysis was performed on the study population at baseline to identify responder 
subgroups. ${ }^{60}$ Despite the use of targeted recruitment criteria, four clusters were identified with differing mepolizumab treatment responses. Of these, one cluster comprising $26 \%$ of the study population was characterized by low baseline eosinophil counts, high symptom burden and prior exacerbation frequency but a poor response to mepolizumab. Raised FeNO was the main criterion for recruitment to the study in this subgroup, suggesting that it is an unreliable surrogate marker of eosinophilic inflammation and mepolizumab responsiveness. This observation is in contrast with several studies that have demonstrated FeNO to be a reliable marker of steroid responsiveness and supports the view that a Th2 high state is not synonymous with eosinophilia.

The cluster demonstrating greatest response to mepolizumab in the analysis was a female-predominant obese, eosinophilic group with airway reversibility and a greater proportion requiring maintenance OCS treatment. Obesity has previously been reported to be associated with a noneosinophilic phenotype that is typically unresponsive to steroids and would not be expected to be appropriate for mepolizumab treatment. ${ }^{49,61}$ However, a recent study reported elevated sputum IL-5 and submucosal eosinophils but normal sputum eosinophils in obese patients with asthma. ${ }^{62}$ Whether this provides evidence for steroid resistance that is overcome with mepolizumab in the DREAM cohort is unclear.

\section{Licensing of mepolizumab: indications for use in clinical practice}

Mepolizumab received license authorization for use by the US Food and Drug Administration (FDA) in April $2015^{63}$ and across the European Union (not the UK) in December $2015 .^{64}$ Both regulatory agencies approved the use of mepolizumab (100 mg sc at four weekly intervals) as add-on treatment in patients above the age of 12 years, with refractory disease, an eosinophilic phenotype and a history of exacerbations. The approved blood eosinophil count to determine an eosinophilic phenotype is $>150$ cells $/ \mu \mathrm{L}$, and no constraint has been placed on the number of prior severe exacerbations.

Mepolizumab has also recently received regulatory approval by the National Institute for Health and Care Excellence (NICE) in the UK. ${ }^{65}$ However, stricter criteria are being applied with patient eligibility based on a blood eosinophil count of $>300$ cells $/ \mu \mathrm{L}$ on one or more occasions in the preceding 12 months and either requiring treatment with maintenance OCSs and/or having a history of four or more exacerbations in the preceding year. The criteria are based on rigorous health economic analyses that report, when met, a cost per quality-adjusted life year (QALY) gained with mepolizumab of less than $£ 30,000$ is achieved if treatment is associated with at least a $50 \%$ reduction in exacerbation frequency. It is recommended that the decision to continue with treatment is based on an assessment of this outcome at the end of 12 months. A general overview of the clinical pathways to inform mepolizumab use in practice, based on the available evidence, is suggested in Figure 3.

\section{Adverse effects}

Mepolizumab has been generally well tolerated in clinical studies to date. Commonly reported side effects include headache and back pain, although these symptoms did not occur at greater frequency in treated patients compared with placebo. Injection site reactions associated with subcutaneous administration are perhaps the most common treatment-related adverse effect.

\section{Using mepolizumab in clinical practice: addressing the unmet need in refractory asthma}

A recently reported observational study estimated approximately $20 \%$ of patients above the age of 12 years with uncontrolled asthma despite the use of high-dose inhaled corticosteroid therapy met US licensing criteria for mepolizumab, a figure that was comparable with the proportion eligible for omalizumab. ${ }^{66}$ It is widely recognized that an eosinophilic phenotype is recognized in about $50 \%$ of patients with severe asthma. The review indicates that only a proportion of severe eosinophilic asthma would meet US licensing criteria. Consistent with this is the observation of Haldar et a $1^{44}$ that only $33 \%$ of patients attending their severe asthma clinic met the eligibility criteria for their study.

The additional licensing constraints in the UK reflect a more conservative approach to regulatory control that is driven by cost. The NICE endorsed eligible population represents a cohort in which the amplitude of benefit justifies economic viability for a state-funded health service. However, it is likely that they comprise only a subgroup of the responder population and although it is clear that mepolizumab and similar therapies only partially address the unmet need in refractory asthma, optimizing their provision through the development of more predictive biomarker algorithms is an essential ongoing objective. 


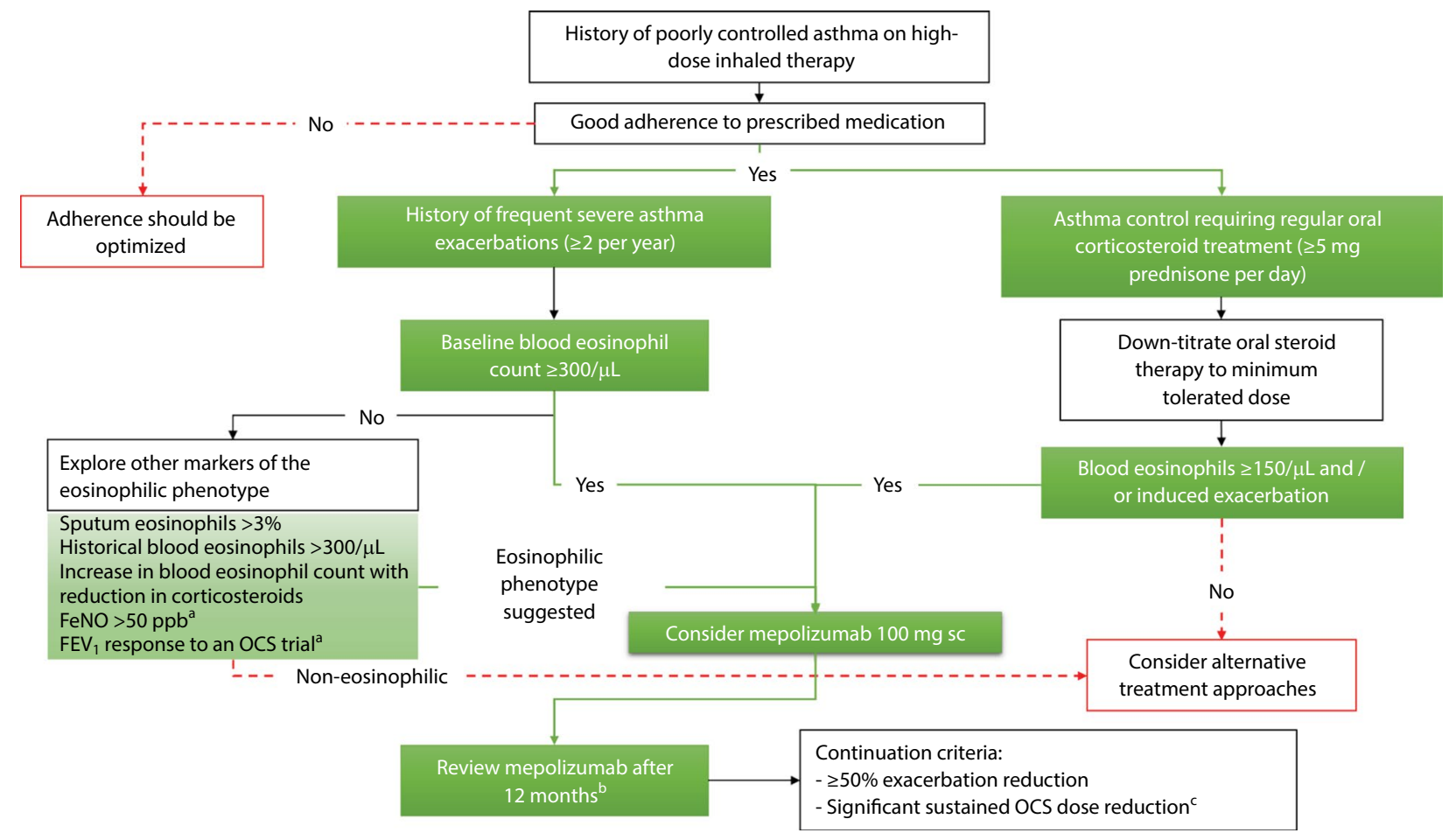

Figure 3 Clinical profiling of patients to inform consideration of mepolizumab therapy.

Notes: aMarkers of Th2 inflammation (indirect measures of eosinophilic inflammation). ${ }^{b}$ NICE recommends a review of response to treatment after 12 months. ${ }^{\circ}$ This is based on clinical judgment.

Abbreviations: NICE, National Institute for Health and Care Excellence; OCS, oral corticosteroid; sc, subcutaneous.

\section{Outcomes after cessation of mepolizumab therapy}

There are little published data of clinical and biological outcomes after mepolizumab treatment is stopped. A post hoc analysis of the Haldar et al's ${ }^{67}$ study cohort remains the only systematic evaluation of this question and reported significant increases in the blood and sputum eosinophil count 3 months and 6 months after stopping treatment with mepolizumab. Exacerbation frequency significantly increased after 6 months, in keeping with this end point being preceded by an increase in underlying eosinophilic inflammation. There was also a worsening of symptom control, with the ACQ- 5 score increasing by 0.59 points over the 12-month period of observation. Supporting the view proposed earlier in this review that mepolizumab may have beneficial effects on symptom control that is masked by clinical trial design. A better understanding of the duration of beneficial clinical effects following prolonged therapy with mepolizumab and other comparable molecular therapies will likely be obtained from real-world clinical experience.

\section{Conclusion}

Mepolizumab is the first specific anti-eosinophil therapy to be licensed for use in the management of refractory asthma. It represents a paradigm shift in the therapeutic portfolio of this population. The developmental program for mepolizumab has illustrated many significant potential pitfalls that may only be avoided by a clear understanding of the relationship of disease pathobiology with clinical disease expression and using this information to characterize the patient profile most likely to benefit. For mepolizumab, this profile may be summarized as evidence of eosinophilic asthma that is associated with either a history of recurrent severe exacerbations or a requirement for maintenance OCS therapy.

The drug pipeline for refractory asthma is currently abundant with molecular therapies at various stages of development, and it is possible that mepolizumab may represent the first step toward a future without OCSs in asthma.

\section{Disclosure}

The author reports no conflicts of interest in this work. 


\section{References}

1. Barnes PJ, Woolcock AJ. Difficult asthma. Eur Respir J. 1998;12(5): 1209-1218.

2. Dougherty RH, Fahy JV. Acute exacerbations of asthma: epidemiology, biology and the exacerbation-prone phenotype. Clin Exp Allergy. 2009;39(2):193-202.

3. Levy ML. The national review of asthma deaths: what did we learn and what needs to change? Breathe (Sheff). 2015;11(1):14-24.

4. Houston JC, De Navasquez S, Trounce JR. A clinical and pathological study of fatal cases of status asthmaticus. Thorax. 1953;8(3):207-213.

5. Huber HL, Koessler K. The pathology of fatal asthma. Arch Intern Med. 1922;30:689-760.

6. Hamid Q, Azzawi M, Ying S, et al. Expression of mRNA for interleukin-5 in mucosal bronchial biopsies from asthma. J Clin Invest. 1991;87(5):1541-1546.

7. Ying S, Humbert M, Barkans J, et al. Expression of IL-4 and IL-5 mRNA and protein product by CD4+ and CD8+ T cells, eosinophils, and mast cells in bronchial biopsies obtained from atopic and nonatopic (intrinsic) asthmatics. J Immunol. 1997;158(7):3539-3544.

8. Walker C, Bode E, Boer L, Hansel TT, Blaser K, Virchow JCJ. Allergic and nonallergic asthmatics have distinct patterns of T-cell activation and cytokine production in peripheral blood and bronchoalveolar lavage. Am Rev Respir Dis. 1992;146(1):109-115.

9. Wardlaw AJ, Dunnette S, Gleich GJ, Collins JV, Kay AB. Eosinophils and mast cells in bronchoalveolar lavage in subjects with mild asthma. Relationship to bronchial hyperreactivity. Am Rev Respir Dis. 1988;137(1):62-69.

10. Bousquet J, Chanez P, Lacoste JY, et al. Eosinophilic inflammation in asthma. N Engl J Med. 1990;323(15):1033-1039.

11. Horn BR, Robin ED, Theodore J, Van Kessel A. Total eosinophil counts in the management of bronchial asthma. $N$ Engl J Med. 1975;292(22):1152-1155.

12. Gibson PG, Dolovich J, Girgis-Gabardo A, et al. The inflammatory response in asthma exacerbation: changes in circulating eosinophils, basophils and their progenitors. Clin Exp Allergy. 1990;20(6):661-668.

13. Pizzichini MM, Pizzichini E, Clelland L, et al. Sputum in severe exacerbations of asthma: kinetics of inflammatory indices after prednisone treatment. Am J Respir Crit Care Med. 1997;155(5):1501-1508.

14. van Leeuwen BH, Martinson ME, Webb GC, Young IG. Molecular organization of the cytokine gene cluster, involving the human IL-3, IL-4, IL-5, and GM-CSF genes, on human chromosome 5. Blood. 1989;73(5):1142-1148.

15. Straumann A, Conus S, Grzonka P, et al. Anti-interleukin-5 antibody treatment (mepolizumab) in active eosinophilic oesophagitis: a randomised, placebo-controlled, double-blind trial. Gut. 2010;59(1):21-30.

16. Gevaert P, Van Bruaene N, Cattaert T, et al. Mepolizumab, a humanized anti-IL-5 mAb, as a treatment option for severe nasal polyposis. J Allergy Clin Immunol. 2011;128(5):988-989.

17. Rothenberg ME, Klion AD, Roufosse FE, et al; Mepolizumab HES Study Group. Treatment of patients with the hypereosinophilic syndrome with mepolizumab. N Engl J Med. 2008;358(12):1215-1228.

18. Kim S, Marigowda G, Oren E, Israel E, Wechsler ME. Mepolizumab as a steroid-sparing treatment option in patients with Churg-Strauss syndrome. J Allergy Clin Immunol. 2010;125(6):1336-1343.

19. Plötz S-G, Simon H-U, Darsow U, et al. Use of an anti-interleukin-5 antibody in the hypereosinophilic syndrome with eosinophilic dermatitis. N Engl J Med. 2003;349(24):2334-2339.

20. Sanderson CJ. Eosinophil differentiation factor (interleukin-5). Immunol Ser. 1990;49:231-256.

21. Nussbaum JC, Van Dyken SJ, von Moltke J, et al. Type 2 innate lymphoid cells control eosinophil homeostasis. Nature. 2013;502(7470):245-248.

22. Kolbeck R, Kozhich A, Koike M, et al. MEDI-563, a humanized anti-IL-5 receptor alpha $\mathrm{mAb}$ with enhanced antibody-dependent cellmediated cytotoxicity function. J Allergy Clin Immunol. 2010;125(6): 1344-1353.e2.
23. Hart TK, Cook RM, Zia-Amirhosseini P, et al. Preclinical efficacy and safety of mepolizumab (SB-240563), a humanized monoclonal antibody to IL-5, in cynomolgus monkeys. JAllergy Clin Immunol. 2001;108(2): 250-257.

24. Flood-Page PT, Menzies-Gow AN, Kay AB, Robinson DS. Eosinophil's role remains uncertain as anti-interleukin-5 only partially depletes numbers in asthmatic airway. Am J Respir Crit Care Med. 2003;167(2):199-204.

25. Menzies-Gow A, Flood-Page P, Sehmi R, Burman J, Hamid Q, Robinson DS et al. Anti-IL-5 (mepolizumab) therapy induces bone marrow eosinophil maturational arrest and decreases eosinophil progenitors in the bronchial mucosa of atopic asthmatics. J Allergy Clin Immunol. 2003;111(4):714-719.

26. Flood-Page P, Menzies-Gow A, Phipps S, et al. Anti-IL-5 treatment reduces deposition of ECM proteins in the bronchial subepithelial basement membrane of mild atopic asthmatics. J Clin Invest. 2003;112(7):1029-1036.

27. Leckie MJ, Ten Brinke A, Khan J, et al. Effects of an interleukin-5 blocking monoclonal antibody on eosinophils, airway hyper-responsiveness, and the late asthmatic response. Lancet. 2000;356(9248):2144-2148.

28. Kips JC, O'Connor BJ, Langley SJ, et al. Effect of SCH55700, a humanized anti-human interleukin-5 antibody, in severe persistent asthma: a pilot study. Am J Respir Crit Care Med. 2003;167(12):1655-1659.

29. Bentley AM, Hamid Q, Robinson DS, et al. Prednisolone treatment in asthma. Reduction in the numbers of eosinophils, T cells, tryptase-only positive mast cells, and modulation of IL-4, IL-5, and interferon-gamma cytokine gene expression within the bronchial mucosa. Am J Respir Crit Care Med. 1996;153(2):551-556.

30. Barnes PJ. How corticosteroids control inflammation: Quintiles Prize Lecture 2005. Br J Pharmacol. 2006;148(3):245-254.

31. Barnes PJ. Mechanisms of action of glucocorticoids in asthma. Am J Respir Crit Care Med. 1996;154(2 pt 2):S21-S26.

32. Büttner C, Lun A, Splettstoesser T, Kunkel G, Renz H. Monoclonal anti-interleukin-5 treatment suppresses eosinophil but not T-cell functions. Eur Respir J. 2003;21(5):799-803.

33. Crimi E, Spanevello A, Neri M, Ind PW, Rossi GA, Brusasco V. Dissociation between airway inflammation and airway hyperresponsiveness in allergic asthma. Am J Respir Crit Care Med. 1998;157(1):4-9.

34. Brightling CE, Bradding P, Symon FA, Holgate ST, Wardlaw AJ, Pavord ID. Mast-cell infiltration of airway smooth muscle in asthma. $N$ Engl J Med. 2002;346(22):1699-1705.

35. Flood-Page P, Swenson C, Faiferman I, et al; International Mepolizumab Study Group. A study to evaluate safety and efficacy of mepolizumab in patients with moderate persistent asthma. Am J Respir Crit Care Med. 2007;176(11):1062-1071.

36. Haldar P, Pavord ID. Noneosinophilic asthma: a distinct clinical and pathologic phenotype. JAllergy Clin Immunol. 2007;119(5):1043-1052.

37. Gibson PG, Simpson JL, Saltos N. Heterogeneity of airway inflammation in persistent asthma : evidence of neutrophilic inflammation and increased sputum interleukin-8. Chest. 2001;119(5):1329-1336.

38. Douwes J, Gibson P, Pekkanen J, Pearce N. Non-eosinophilic asthma: importance and possible mechanisms. Thorax. 2002;57(7):643-648.

39. Pavord ID, Brightling CE, Woltmann G, Wardlaw AJ. Non-eosinophilic corticosteroid unresponsive asthma. Lancet. 1999;353(9171):2213-2214.

40. Jatakanon A, Lim S, Barnes PJ. Changes in sputum eosinophils predict loss of asthma control. Am J Respir Crit Care Med. 2000;161(1): 64-72.

41. Green RH, Brightling CE, McKenna S, et al. Asthma exacerbations and sputum eosinophil counts: a randomised controlled trial. Lancet. 2002;360(9347):1715-1721.

42. Jayaram L, Pizzichini MM, Cook RJ, et al. Determining asthma treatment by monitoring sputum cell counts: effect on exacerbations. Eur Respir J. 2006;27(3):483-494.

43. Chlumsky J, Striz I, Terl M, Vondracek J. Strategy aimed at reduction of sputum eosinophils decreases exacerbation rate in patients with asthma. J Int Med Res. 2006;34(2):129-139. 
44. Haldar P, Brightling CE, Hargadon B, et al. Mepolizumab and exacerbations of refractory eosinophilic asthma. N Engl J Med. 2009;360(10): 973-984.

45. Nair P, Pizzichini MM, Kjarsgaard M, et al. Mepolizumab for prednisone-dependent asthma with sputum eosinophilia. $N$ Engl J Med. 2009;360(10):985-993.

46. Weller PF. The immunobiology of eosinophils. NEnglJMed. 1991;324(16): 1110-1118.

47. Mould AW, Ramsay AJ, Matthaei KI, Young IG, Rothenberg ME, Foster PS. The effect of IL-5 and eotaxin expression in the lung on eosinophil trafficking and degranulation and the induction of bronchial hyperreactivity. J Immunol. 2000;164(4):2142-2150.

48. Hogan SP, Rosenberg HF, Moqbel R, et al. Eosinophils: biological properties and role in health and disease. Clin Exp Allergy. 2008;38(5):709-750.

49. Haldar P, Pavord ID, Shaw DE, et al. Cluster analysis and clinical asthma phenotypes. Am J Respir Crit Care Med. 2008;178(3):218-224.

50. Pavord ID, Korn S, Howarth P, et al. Mepolizumab for severe eosinophilic asthma (DREAM): a multicentre, double-blind, placebo-controlled trial. Lancet. 2012;380(9842):651-659.

51. Ortega HG, Liu MC, Pavord ID, et al. Mepolizumab treatment in patients with severe eosinophilic asthma. NEngl J Med. 2014;371(13): 1198-1207.

52. Bel EH, Wenzel SE, Thompson PJ, et al; SIRIUS Investigators. Oral glucocorticoid-sparing effect of mepolizumab in eosinophilic asthma. N Engl J Med. 2014;371(13):1189-1197.

53. Pouliquen IJ, Kornmann O, Barton SV, Price JA, Ortega HG. Characterization of the relationship between dose and blood eosinophil response following subcutaneous administration of mepolizumab. Int J Clin Pharmacol Ther. 2015;53(12):1015-1027.

54. Rosenberg HF, Phipps S, Foster PS. Eosinophil trafficking in allergy and asthma. J Allergy Clin Immunol. 2007;119(6):1302-1303.

55. Smith AD, Cowan JO, Filsell S, et al. Diagnosing asthma: comparisons between exhaled nitric oxide measurements and conventional tests. $\mathrm{Am}$ J Respir Crit Care Med. 2004;169(4):473-478.

56. Parulekar AD, Atik MA, Hanania NA. Periostin, a novel biomarker of TH2-driven asthma. Curr Opin Pulm Med. 2014;20(1):60-65.

57. Ortega HG, Yancey SW, Mayer B, et al. Severe eosinophilic asthma treated with mepolizumab stratified by baseline eosinophil thresholds: a secondary analysis of the DREAM and MENSA studies. Lancet Respir Med. 2016;4(7):549-556.
58. Everitt B, Landau S, Leese M, Stahl D. Cluster Analysis. 5th ed. Chichester: Wiley Interscience; 2011.

59. Moore WC, Meyers DA, Wenzel SE, et al; National Heart, Lung, and Blood Institute's Severe Asthma Research Program. Identification of asthma phenotypes using cluster analysis in the Severe Asthma Research Program. Am J Respir Crit Care Med. 2010;181(4): 315-323.

60. Ortega H, Li H, Suruki R, Albers F, Gordon D, Yancey S. Cluster analysis and characterization of response to mepolizumab: a step closer to personalized medicine for patients with severe asthma. Ann Am Thorac Soc. 2014;11(7):1011-1017.

61. Scott HA, Gibson PG, Garg ML, Wood LG. Airway inflammation is augmented by obesity and fatty acids in asthma. Eur Respir J. 2011;38(3): 594-602.

62. Desai D, Newby C, Symon FA, et al. Elevated sputum interleukin-5 and submucosal eosinophilia in obese individuals with severe asthma. Am $J$ Respir Crit Care Med. 2013;188(6):657-663.

63. FDA [webpage on the Internet]. FDA approved drug products: Nucala; 2015 [cited February 6, 2017]. Available from: http://www. accessdata.fda.gov/scripts/cder/daf/index.cfm? event=overview. process\&ApplNo=125526. Accessed May 12, 2017.

64. European Medicines Agency [webpage on the Internet]. European Medicines Agency - Nucala; 2015 [cited February 6, 2017]. Available from: http://www.ema.europa.eu/ema/index.jsp?curl=pages/medicines/ human/medicines/003860/human_med_001933.jsp\&mid=WC0 b01ac058001d124. Accessed May 12, 2017.

65. National Institute for Health and Clinical Excellence [webpage on the Internet]. Mepolizumab for treating severe refractory esoinophilic asthma. Technol Apprais Guid; 2016. Available from: https://www.nice. org.uk/guidance/ta431/chapter/1-Recommendations. Accessed May 12, 2017.

66. Suruki RY, Gunsoy N, Shin J-Y, et al. The identification and description of severe asthma patients in a cross-sectional study- the ideal study. J Allergy Clin Immunol. 2017;137(2):AB103.

67. Haldar P, Brightling CE, Singapuri A, et al. Outcomes after cessation of mepolizumab therapy in severe eosinophilic asthma: a 12-month follow-up analysis. J Allergy Clin Immunol. 2014;133(3):921-923.
Biologics: Targets and Therapy

\section{Publish your work in this journal}

Biologics: Targets and Therapy is an international, peer-reviewed journa focusing on the patho-physiological rationale for and clinical application of Biologic agents in the management of autoimmune diseases, cancers or other pathologies where a molecular target can be identified. This journal is indexed on PubMed Central, EMBase, and Scopus.

\section{Dovepress}

The manuscript management system is completely online and includes a very quick and fair peer-review system, which is all easy to use. Visit http://www.dovepress.com/testimonials.php to read real quotes from published authors. 